\title{
Malnutrition and Child Labor
}

\author{
Garance Genicot \\ Georgetown University \\ 2001, revised April 2004.
}

\begin{abstract}
In both pre-industrial societies and in contemporary developing economies, it is common to find; (a) families, including children, performing regular work, be it in family farms or urban factories; and (b) a positive link between a person's consumption and his or her productivity. This paper argues that there is a natural reason for the concurrence of (a) and (b), and that this link represents an aspect of child labor that had not been identified so far, although potentially consequent to child labor policies. It is sensible to expect households to be characterized by intra-household altruism. It follows that an increased income of one individual increases the consumption of all household members. An implication of this is that when an employer employs an adult and pays the adult a high wage in order to enhance the worker's productivity, part of this high wage ends up augmenting the consumption of the laborer's children, thereby making the children themselves more productive. One way in which the employer can prevent this leakage and internalize the externality is to employ the children as well. This explains the higher incidence of family labor, whether in factories or on farms, in poor societies where (b) is more likely to be true.
\end{abstract}

JEL Classification Numbers: D10, J30, 012.

Key Words: child labor, nutrition, efficiency wage.

The author is grateful to Kaushik Basu, Jean-Marie Balland, Luis-Felipe Lopez Calva, Stergios Skaperdas, T.N. Srinivasan and two anonymous referees for their comments on an earlier draft. The paper has also benefited from seminar presentations at Cornell University and at the North-Eastern Universities Development Consortium in Yale University. Please address all correspondence to gg58@georgetown.edu. 


\section{Introduction}

Malnutrition and child labor are two facts of life for many families in poor societies. Contemporary and historical evidence suggests that the vast majority of working children originate from very poor families whose members undernourishment is common. ${ }^{1}$ This paper suggests that there may be fundamental reasons for the coexistence of undernourishment and child labor.

At low levels of income, there is a positive relationship between the nutritional intake of a laborer and the productivity of his work. To the extent that nutritional deprivation constrains the physiological performances of the laborer, it may be in the employers' interest to pay a wage higher than the market-clearing wage; an "efficiency wage." The concept of nutritional efficiency wage, introduced in the economic literature by Leibenstein in 1957, was formally modelled by both Mirrlees and Rodgers in 1975 . This gave rise to a long tradition of theoretical models of nutrition-based efficiency wage in the development literature (see for instance Stiglitz 1976; Dasgupta and Ray 1986, 1987; Guha 1989; Basu 1992; Ray and Streufert 1993; and Dasgupta 1993, 1997). In addition, several empirical studies provide indirect support for the theory. ${ }^{2}$ Despite this interest, the consequences of nutritional efficiency considerations and intra-household redistribution on child labor have not been investigated so far.

A critical finding of this paper is that the presence of children weakens the link between the parents' nutritional intake and their earnings. A laborer who is paid a high

\footnotetext{
${ }^{1}$ Anderson 1971, Goldin 1979, Olsson 1986, Chandrasekhar 1990, Basu 1999, Grootaert and Kanbur 1995 among others, argue that poverty of families is a precondition for child labor.

${ }^{2}$ The strongest support of the relation between energy intake and productivity are to be found in the Minnesota experiment by Keys et al. (1950); in a survey of energy expenditure in the major industries during the WWII, see FFHC (1962); in the series of longitudinal studies conducted among Guatemalan sugarcane cutters and loaders, see among others Immink and Viteri (1981); and in Wolgemuth et al. (1982)'s experiences on Kenyan construction workers. Fogel and Engerman's (1974) detailed description of slaves' diet also provides strong evidence in favor of the nutrition-efficiency wage. For good reviews of this literature, see Bliss and Stern (1978), Dasgupta (1993), and Strauss and Thomas (1998).
} 
wage by his employer in order to enhance his productivity devotes part of his remuneration to his children's consumption, thereby making the children more productive. This leakage can be substantial, especially if parents are altruistic and if they have many children. Employers may thus find it more profitable to hire whole families to internalize the externality generated by the intra-household redistribution, even when children themselves are not particularly productive. Therefore, an employer choosing between two adults, one whose children work and another whose children do not work, will find the former adult more attractive. This, in the presence of unemployment, creates incentives for adults to send their children to work. It is worth noting that this simple and intuitive result is at odds with the conventional wisdom that, in the presence of wage rigidity or unemployment, employers prefer adult laborers. ${ }^{3}$

The main objective of this paper is to identify and model this causal link between undernourishment and child labor, and analyze its implications for child labor policies. The model has two additional consequences. Any income to non working members of the household, such as public assistance or home production, increases the productivity of its working members at no cost for the employer, thereby involuntarily "subsidizing" their labor. Additionally, the paper shows that the effects of technological progress, in the sense of an increase in labor productivity, is consistent with the pattern of initial increase in child labor followed by a sudden decline observed in history.

The next section briefly describes some of the historical evidence which motivated the paper. Section 3 presents the model and analyzes the interaction between food deprivation and the labor market. Different results concerning household and child labor are derived. Section 4 discusses the design of policy interventions related to child labor

\footnotetext{
${ }^{3}$ Grootaert and Kanbur (1995, p.194) for instance argue "In competitive markets where wages are flexible, children can substitute for adults in the market place. Where wages are at a floor level, whether due to legislation, collective action or because they have reached an adult subsistence minimum, the employer will prefer adult workers assuming that their productivity is higher than that of children."
} 
in labor markets characterized by undernourishment of the labor force. Finally, Section 5 concludes the analysis.

\section{Historical Evidence}

This essay has been largely motivated by reports on the extent and conditions of child labor in pre-industrial and industrial Europe and United States. Particularly relevant for this paper is the frequency with which members from a same household were working together for a common employer.

Most British country mills in the 18th and 19th century were organized on a family employment basis (see among others Cruickshank 1981; Bolin-Hort 1989; and Horrell and Humphries 1995). Similarly, family labor was the prevailing employment system in the early 19th century in most Eastern US states. Some recruitment ads were explicitly directed towards entire families, ${ }^{4}$ and wages were often set on a family basis. "The factory treated the domestic family, not the individual, as the unit of production." [Wallace 1978, p.172]. During the last decades of the 19th century, the cotton industry in the Southern US states expanded dramatically. By the turn of the century, the cotton industry in the South relied almost completely on the recruitment of impoverished families. ${ }^{5}$ The persistence of family employment practices in the Southern mills must be seen as the major reason behind the high proportion of children in the work force. ${ }^{6}$ "Firms were not buying individual unit of labor but a family package. The supply price of any

\footnotetext{
${ }^{4}$ See Massachusetts Senate Document 21 (1868), quoted in Saxonhouse and Wright (1984).

${ }^{5}$ See Saxonhouse and Wright (1984) and Hall et al. (1986).

${ }^{6}$ In the Southern States, $15.6 \%$ of all children under 12, 87.6\% of all 13 and 14 year old, and $96.2 \%$ of all 14 and 15 old were working [US Senate Documents 1910-11: v.I pp.26,424-5]. The 1905 Census of Manufactures recorded proportions of children below 16 in the workforce ranging from $12 \%$ in Virginia to $27 \%$ in Alabama. Moreover, investigations have revealed that wage books and census figures seriously underestimated the extent of child labor, since the younger children were often brought in as "helpers" to other siblings, and did not receive separate wages in order to evade the regulations.
} 
one type of labor was low, given that the family wage (the sum of the earnings of the members) was high enough to keep the family in the village. Hence, the wage structure was largely arbitrary." [Saxonhouse and Wright 1984, pp.7-8, 18].

Also very relevant are the reports of widespread poverty and undernourishment. ${ }^{7}$ Low income appears to be the main motive for child labor supply in 19th century England (Anderson, 1971). Circumstances were therefore present for the nutrition-based efficiency theory to play a role, and accordingly, unemployment levels were high (see Bolin-Hort, 1989, and Cunningham, 1990).

It is worth noting that the concept of efficiency wage is acknowledged in the literature of the industrial revolution. West (1826) and Marx (1867) for instance explicitly distinguish between the hourly wage paid and the real price of labor. Marx insists on the fact that "the value of labour power was determined not only by the labour-time necessary to maintain individual adult labourer, but also by that necessity to maintain his family." [Marx 1867, Part 4 Ch.XV(3a) p.395]. He writes: "The same holds as to the income of the labourer's family, as soon as the quantity of labour expanded by the head of the family is increased by the labour of the members of his family. There are therefore methods of lowering the price of labour independent on the reduction of the nominal daily or weekly wages." [Marx 1867, p.545].

Over time, it was observed that the incidence of child labor first increased dramatically. Although already pervasive for children at family farms, workshops and home-

\footnotetext{
${ }^{7}$ Foster (1967) concludes that $35 \%$ of the unskilled labourers in Oldham, England were at or below the subsistence line in 1849 and $78 \%$ in 1847 when both prices and unemployment were higher $( \pm 20 \% \& 50 \%$ respectively over the whole population). See also Shammas (1990). In the US cotton South, a federal study of mill workers' household budgets conducted in 1907-08 revealed that " $20 \%$ of these people are living in the direst poverty. They are underfed, or underclothed or they have not enough fire to keep them warm. Another $51 \%$ were living in poverty of one degree or another. Some are barely above the starvation line, others have enough for food and clothing and a few of the other things considered as necessaries... yet they feel the pinch of poverty somewhere." [U.S. Senate V.16: Family Budgets of Typical Cotton-Mill Workers, p.170].
} 
based industries, it reached unprecedented levels during the early industrial revolution. Yet, after a period of high incidence, most countries witnessed a rapid decline in child labor levels. ${ }^{8}$ Child labor legislation certainly helped, but most scholars agree that it did little more than hasten this decline. ${ }^{9}$ Authors such as Kuczynski (1958) or Ludwig (1965) relate the decline in child labor to the increase in productivity and emphasize technological progress. ${ }^{10}$ Others, like Olsson (1986) or Berglund (1982) however find a strictly technological explanation unsatisfying. ${ }^{11}$ Nardinelli (1980) argues that the two main causal factors behind the decline of child labor in the late 19th century British textiles were technological changes and rising living standards among working class adults. As shown below, this is the very combination of effects that will result in an initial increase followed by a sudden decline in child labor in our model.

\section{Model}

Premises of the Model. Assume a large number $n$ of identical households each composed of an adult $(A)$ and a child $(B)$. Each household member is endowed with one unit of labor and can work or not $l_{A}, l_{B} \in\{0,1\}$, where 1 denotes work and 0 non-work. Adult and child wages are denoted $w_{A}$ and $w_{B}$ respectively, and $g$ is the alternative revenue available to the unemployed. Throughout the paper, an alternative source of income is taken to mean any source of revenue that is a substitute for work under consideration, e.g. public assistance, begging or home production. Hence, the household income is

\footnotetext{
${ }^{8}$ Child labor suddenly decreased and almost vanished in Britain within a couple of decades in the late 19th and early 20th centuries. In Italy, child labor was very high until 1950, but had almost disappeared thirty years later. Catalonia also experienced an initial increase in child labor before a rapid decline.

${ }^{9}$ See Heywood 1988, Cunningham and Viazzo 1996, or Kuczynski 1958. Olsson (1986) clearly shows that child labor levels declined drastically well before the implementation of a restrictive legislation.

${ }^{10}$ Kuczynski, J. (1958), 'Geschichte der Kinderarbeit in Deutschland', Berlin; and Ludwig, K-H (1965), 'Die Fabrikarbeit von Kindern im 19. Jahrhundert. Ein Problem der Technikgeschichte', Vierteljahrschrift fur Social- und Wirtschaftgeschichte [quoted in Bolin-Hort 1989, p.11].

${ }^{11}$ Berglund, B. (1982), 'Industriarbetarklassens formering. Arbete och teknisk förändring vid tre svenska fabriker, Göteborg, [quoted in Bolin-Hort 1989, p.13].
} 
$Y=l_{A} w_{A}+l_{B} w_{B}+\left(2-l_{A}-l_{B}\right) g$.

There is a unique consumption good whose price is normalized to one. The adult chooses his and his child's consumptions, $c_{A}$ and $c_{B}$, and labor supplies, $l_{A}$ and $l_{B}$, in order to maximize a household utility function $U\left(c_{A}, c_{B}, l_{A}, l_{B}\right)$ subject to $c_{A}+c_{B} \leq Y$. In particular, we shall assume the household preferences to be

$$
U\left(c_{A}, c_{B}, l_{A}, l_{B}\right)=u\left(c_{A}^{1-\alpha} c_{B}^{\alpha}\right)-l_{B} v_{B}\left(c_{A}+c_{B}\right)-l_{A} v_{A}\left(c_{A}+c_{B}\right)
$$

where $\alpha \in(0,1)$ represents the level of altruism of the parent for his child, and where $u()$ is increasing, smooth, concave and bounded, with $\lim _{c \rightarrow 0} u(c)=-\infty \cdot v_{A}$ and $v_{B}$ are the disutility from adult and child labor that may depend on aggregate income. Hence, the consumption functions take the following forms

$$
c_{A}(Y)=(1-\alpha) Y ; \text { and } c_{B}(Y)=\alpha Y
$$

The interrelation between consumption and work productivity is represented by the nutrition-productivity functions $h_{i}(c)$, where $h_{i}(c)$ gives the "efficiency units" of labor corresponding to a consumption of $c$ for the work of an adult $(i=A)$ or a child $(i=$ $B)$. Initially, most of the nutrition goes into maintaining resting metabolism and very little energy is left to sustain physical activity. Once the basic body's requirements are taken care of, nutritional intake significantly increases one's work capacity as most of the additional energy is used to perform work. To be sure, the relation between work capacity and consumption exhibits diminishing returns beyond a certain level of nutritional intake. ${ }^{12}$ Assuming the nutrition-productivity functions to be continuous and differentiable, these considerations imply the following shape for the curves. First,

\footnotetext{
${ }^{12}$ See Clark and Haswell, 1970, and Bliss and Stern, 1978.
} 
$h_{i}(0)=0$. Then, over consumptions in $\left(0, \underline{c}_{i}\right), h_{i}^{\prime}(c)>0$ and $h_{i}^{\prime \prime}(c)>0 \forall c \leq \underline{c}_{i}$. Beyond $\underline{c}_{i}$ and up to some level of consumption $\bar{c}_{i}, h_{i}^{\prime}(c)>0$ and $h_{i}^{\prime \prime}(c)<0$. Above $\bar{c}_{i}$ the relationship between consumption and productivity disappears, $h_{i}(c)=\bar{h}_{i} \forall c \geq \bar{c}_{i}$. Moreover, children have lower subsistence needs than adults, so that $\underline{c}_{B} \leq \underline{c}_{A}$; but we assume that, beyond a certain level of consumption, adults are more productive than children, $\bar{h}_{A}>\bar{h}_{B}$. As conventional in the efficiency-wage literature, we assume that there is no time-lag between consumption and the increase in efficiency, and that employers perceive fully the relation between wage and labor productivity. ${ }^{13}$

There are $m$ firms in the economy indexed by $j \in\{1,2, \ldots m\}$ who have technology $f\left(H_{j}\right)+\widetilde{\varepsilon}$, where $H_{j}$ is the total number of efficiency units used in the production of firm $j, f$ satisfies the Inada conditions, and $\widetilde{\varepsilon}$ is an independent random variable with zero mean. Implicit to this formulation is the assumption that child and adult labor are substitutes and enter the production function only through their efficiency. All firms being identical, we drop the subscript $j$ hereafter. The noise in the production function makes it impossible for employers to back out the worker's consumption from the amount produced. A firm's problem consists in choosing how many workers of each type to hire, $\mathbf{n}=\left\{n_{A}, n_{B}, n_{H}\right\}-$ where $n_{H}$ is the number of full households, $n_{A}$ the number of adults without their children and $n_{B}$ the number of children alone--, and the wage to pay them, $\mathbf{w}=\left\{w_{A}, w_{B}, w_{H}\right\}$, in order to maximize its expected profit:

$$
\begin{aligned}
& \max _{\mathbf{w}, \mathbf{n}} E \pi(\mathbf{w}, \mathbf{n})=f\left[n_{A} h_{A}\left(c_{A}\left(w_{A}+g\right)\right)+n_{B} h_{B}\left(c_{B}\left(w_{B}+g\right)\right)+n_{H} h_{H}\left(w_{H}\right)\right]-\sum_{i \in\{A, B, H\}} n_{i} w_{i} \\
& \text { subject to } w_{i} \geq w_{i}^{*} \text { for all } i \in\{A, B, H\} .
\end{aligned}
$$

\footnotetext{
${ }^{13}$ Naturally, there are substantial interpersonal variations in nutritional requirements and the increased efficiency from consumption is not simultaneous. Yet, employers seem to be aware of the existence of a relation between consumption and efficiency at low level of income. It can be argued that they learn about the shape of that relation by trial and error. For a very convincing study of the BMI as an observable signal of productivity and its impact on labor market in the Philippines, see Foster and Rosenzweig $(1993,1994)$. The simultaneity between consumption and increased efficiency should be seen as a steady state condition.
} 
where $h_{H}\left(w_{H}\right)=h_{A}\left(c_{A}\left(w_{H}\right)\right)+h_{B}\left(c_{B}\left(w_{H}\right)\right)$ is the efficiency of a household with income $w_{H}$ and $w_{i}^{*}$ is the market-clearing wages for labor of type $i$.

Efficiency Wage. From (3.3), we can derive the labor demands

$$
\widetilde{n_{i}}=\max \left\{n_{i} \mid f^{\prime}(H) \leq \frac{w_{i}}{h_{i}}\right\}
$$

where $H=n_{A} w_{A}+n_{B} w_{B}+n_{H} w_{H}$. Firms demand only the type of labor $i$ that has the highest efficiency per unit of cost $\frac{h_{i}}{w_{i}}$. We shall make the tie-breaking assumption that, when indifferent, employers prefer adults only or children only to household labor. The wages that maximize the efficiency per unit of cost, and therefore expected profits, are called efficiency wages and are given by

$$
\widehat{w}_{i}=\arg \max \frac{h_{i}\left(c_{i}\left(w_{i}+g\right)\right)}{w_{i}} \quad i \in\{A, B\} \quad \text { and } \quad \widehat{w}_{H}=\arg \max \frac{h_{H}\left(w_{H}\right)}{w_{H}} .
$$

Denote $\widehat{c}_{A}$ and $\widehat{c}_{B}$ the efficiency levels of consumption, or levels of consumption that maximize the efficiency per unit of cost of an adult, $\frac{h_{A}(c)}{c}$, and of a child, $\frac{h_{B}(c)}{c}$. We are interested in explaining child labor in situations where children are per se less productive. Hence, we shall assume that the minimum cost per efficiency unit of an adult is lower than a child's: A1. $\frac{h_{A}\left(\widehat{c}_{A}\right)}{\widehat{c}_{A}}>\frac{h_{B}\left(\widehat{c}_{B}\right)}{\widehat{c}_{B}}$.

Demand Effects for Family and Child Labor. The following proposition summarizes the labor demand effects favoring adult, household or child labor.

Proposition 1 If the reservation wages for participation in the labor market are not binding and the population is large, there are threshold levels of altruism $\underline{\alpha}(g)$ and $\bar{\alpha}(g)$ such that employers hire: (i) adults only for $\alpha \leq \underline{\alpha}(g)$; (ii) households for all $\alpha \in$ ]$\underline{\alpha}(g), \bar{\alpha}(g)[$; and (iii) children only for $\alpha \geq \bar{\alpha}(g)$. 
Moreover, there are values of alternative source of income $\bar{g}>\underline{g}>0$ such that (a) for all $g<\underline{g}$, household labor is always preferred $\underline{\alpha}(g)=0$ and $\bar{\alpha}(g)=1$; and (b) for any $g \geq \bar{g}$, household labor is dominated $\underline{\alpha}(g)=\bar{\alpha}(g)$.

Proof. If the reservation wages are low and the population is large, market-clearing wages are lower than efficiency wages. Paying a given type of labor less than the efficiency wage actually reduces its efficiency per unit of cost. Hence, firms pay the efficiency wage. Consider first the case where $g=0$. For all $i \in\{A, B\}$ and $w>0, h_{i}\left(c_{i}(w)\right)>0$ so that $\frac{h_{H}(w)}{w}>\frac{h_{i}\left(c_{i}(w)\right)}{w}$. At a given wage, the efficiency per unit of cost is higher for family labor than for adults or children only. In the absence of alternative income, employers strictly prefer to employ entire households: $\underline{\alpha}(0)=0$ and $\bar{\alpha}(0)=1$.

Consider now higher values of $g$. Our first objective is to show that $\underline{\alpha}(g)$ is increasing in $g$ for $g \in[\underline{g}, \bar{g}]$. To do so, we first need to show that, for a given $g \in[\underline{g}, \bar{g}]$, $\max _{w} \frac{h_{A}\left(c_{A}(w+g)\right)}{w}-\max _{w_{H}} \frac{h_{H}\left(w_{H}\right)}{w_{H}}$ is decreasing in $\alpha$, that is

$$
\frac{d}{d \alpha}\left(\frac{h_{A}\left((1-\alpha)\left(\widehat{w}_{A}+g\right)\right)}{\widehat{w}_{A}}\right) \leq \frac{d}{d \alpha}\left(\frac{h_{H}\left(\widehat{w}_{H}\right)}{\widehat{w}_{H}}\right) .
$$

Expanding it and invoking the envelope theorem, this inequality simplifies to

$$
h_{A}^{\prime}\left((1-\alpha)\left(\widehat{w}_{A}+g\right)\right)\left(1+\frac{g}{\widehat{w}_{A}}\right) \geq h_{A}^{\prime}\left((1-\alpha) \widehat{w}_{H}\right)-h_{B}^{\prime}\left(\alpha \widehat{w}_{H}\right)
$$

It follows from the definition of the efficiency wages (3.5) that

$$
(1-\underline{\alpha}) h_{A}^{\prime}\left((1-\underline{\alpha})\left(\widehat{w}_{A}+g\right)\right)=\frac{h_{A}\left((1-\underline{\alpha})\left(\widehat{w}_{A}+g\right)\right)}{\widehat{w}_{A}} \&(1-\underline{\alpha}) h_{A}^{\prime}\left((1-\underline{\alpha}) \widehat{w}_{H}\right)+\underline{\alpha} h_{B}^{\prime}\left(\underline{\alpha} \widehat{w}_{H}\right)=\frac{h_{H}\left(\widehat{w}_{H}\right)}{\widehat{w}_{H}} .
$$

Combining this information with the fact that at $\underline{\alpha}$ the efficiency per unit of cost of 
adults only and households are the same, we see that

$$
(1-\underline{\alpha}) h_{A}^{\prime}\left((1-\underline{\alpha})\left(\widehat{w}_{A}+g\right)\right)=(1-\underline{\alpha}) h_{A}^{\prime}\left((1-\underline{\alpha}) \widehat{w}_{H}\right)+\underline{\alpha} h_{B}^{\prime}\left(\underline{\alpha} \widehat{w}_{H}\right) .
$$

Now, a sufficient condition for (3.6) to hold is that

$$
(1-\alpha) h_{A}^{\prime}\left((1-\alpha)\left(\widehat{w}_{A}+g\right)\right) \geq(1-\alpha) h_{A}^{\prime}\left((1-\alpha) \widehat{w}_{H}\right)-(1-\alpha) h_{B}^{\prime}\left(\alpha \widehat{w}_{H}\right) .
$$

For $\alpha=\underline{\alpha}$, using (3.7), inequality (3.8) reduces to $h_{B}^{\prime}\left(\underline{\alpha} \widehat{w}_{H}\right) \geq 0$. This clearly holds. Consequently, for any $\alpha \leq \underline{\alpha}$, the efficiency per unit of cost of adults only will be no less than the household one, and from the definition of the efficiency wages (3.5):

$$
(1-\alpha) h_{A}^{\prime}\left((1-\alpha)\left(\widehat{w}_{A}+g\right)\right) \geq(1-\alpha) h_{A}^{\prime}\left((1-\alpha) \widehat{w}_{H}\right)+\alpha h_{B}^{\prime}\left(\alpha \widehat{w}_{H}\right) .
$$

This implies that inequality (3.8) is true and therefore (3.6) holds.

Note that $\frac{h_{A}\left(c_{A}\left(\widehat{w}_{A}+g\right)\right)}{\widehat{w}_{A}}$ is increasing in $g$ while $\frac{h_{H}\left(\widehat{w}_{H}\right)}{\widehat{w}_{H}}$ is unaffected by it. If a household member does not work and benefits from public assistance, it increases the efficiency per unit of cost of the other household member. In contrast, hiring the household means forgoing the alternative source of income. To keep the efficiency per unit of cost equal, if $g$ increases then $\alpha$ needs to increase. Hence, $\underline{\alpha}(g)$ is increasing in $g$ for $g \in[\underline{g}, \bar{g}]$. A similar argument can be made to show that $\bar{\alpha}(g)$ is decreasing in $g$ for $g \in[\underline{g}, \bar{g}]$.

To be sure, for a sufficiently high alternative source of revenue $g$, employers would never hire households and $\underline{\alpha}(g)=\bar{\alpha}(g)$. This threshold level $\bar{g}$ is the smallest $g$ such that $\max _{i \in\{A, B\}}\left\{\frac{h_{i}\left(c_{i}\left(\widetilde{w}_{i}+g\right)\right)}{\widetilde{w}_{i}}\right\} \geq \frac{h_{H}\left(\widehat{w}_{H}\right)}{\widehat{w}_{H}}$ for all $\alpha \in(0,1)$, where $\widetilde{w}_{i}=\max \left\{\widehat{w}_{i}(\bar{g}), w_{i}^{*}(\bar{g})\right\}$, and where $w_{A}^{*}(g)$ stands for the market-clearing wage. ${ }^{14}$

\footnotetext{
${ }^{14}$ Naturally, looking at very high levels of public assistance $g$ assuming that the reservation wage does not bind would be inconsistent. However, it can be easily checked that $\widehat{w}_{i}(g)$ decreases more than
} 
Alternative sources of income such as begging, gleaning, assistance from poor laws are often very low and unemployment benefits are most often non-existent, such that, from Proposition 1, we expect household labor to prevail. Given that children are not very productive (A1), child labor results purely from the externalities generated by the redistribution within the household. Paradoxically, the more altruistic the parents the more likely child labor is. The existence of public assistance could even result in an equilibrium where only children work, and parents receive the public assistance. Parental altruism acts here as a subsidy for child labor. If employers could choose the consumption allocation within households, they would employ adults only and allocate all consumption to them. The widespread practice of employers to offer meals to workers as part of their remuneration in rural agricultural societies is another way for employers to internalize part of the externality. ${ }^{15}$

Figure 1 illustrates the situation for $g=0$. Let $\widehat{n}_{H}$ be the firm's household labor demand at the household efficiency wage as given by (3.4). If $\widehat{n}_{H} m \leq N$, there is no excess demand of labor and each firm employs $\widehat{n}_{H}$ at wage $\widehat{w}_{H}$. If at $\widehat{w}_{H}$ there is excess supply of household labor, $\widehat{n}_{H} m<N$, the economy is characterized by unemployment of some households and employment of both the child and the adult in other households. Unemployed households are unable to bid down the wage since wages lower than the efficiency wage decreases the employer's profit.

It is worth noting that, when alternative sources of income are low and there is excess labor supply, employers clearly prefer to employ childless adults to a parent and its child, since for the former the wage paid and the workers' consumption coincide. ${ }^{16}$

proportionally with $g$, such that $\bar{g}$ is small.

${ }^{15}$ Partially, since it concerns only one meal and not other relevant consumptions such as medications, blankets, etc. Moreover, monitoring whether the worker does not bring back home part of his meal could be costly.

${ }^{16}$ Employers would pay an efficiency wage of $\widehat{c}_{A}$ to a childless adult and $\widehat{w}_{H}$ to a household. Let $c_{A}+c_{B}=\widehat{w}_{H}$. First, if $\frac{h_{A}\left(c_{A}\right)}{c_{A}}>\frac{h_{B}\left(c_{B}\right)}{c_{B}}$ then $\frac{h_{A}\left(c_{A}\right)}{c_{A}}>\frac{h_{H}\left(\widehat{w}_{H}\right)}{\widehat{w}_{H}}=\frac{h_{A}\left(c_{A}\right)+h_{B}\left(c_{B}\right)}{c_{A}+c_{B}}$. It then 


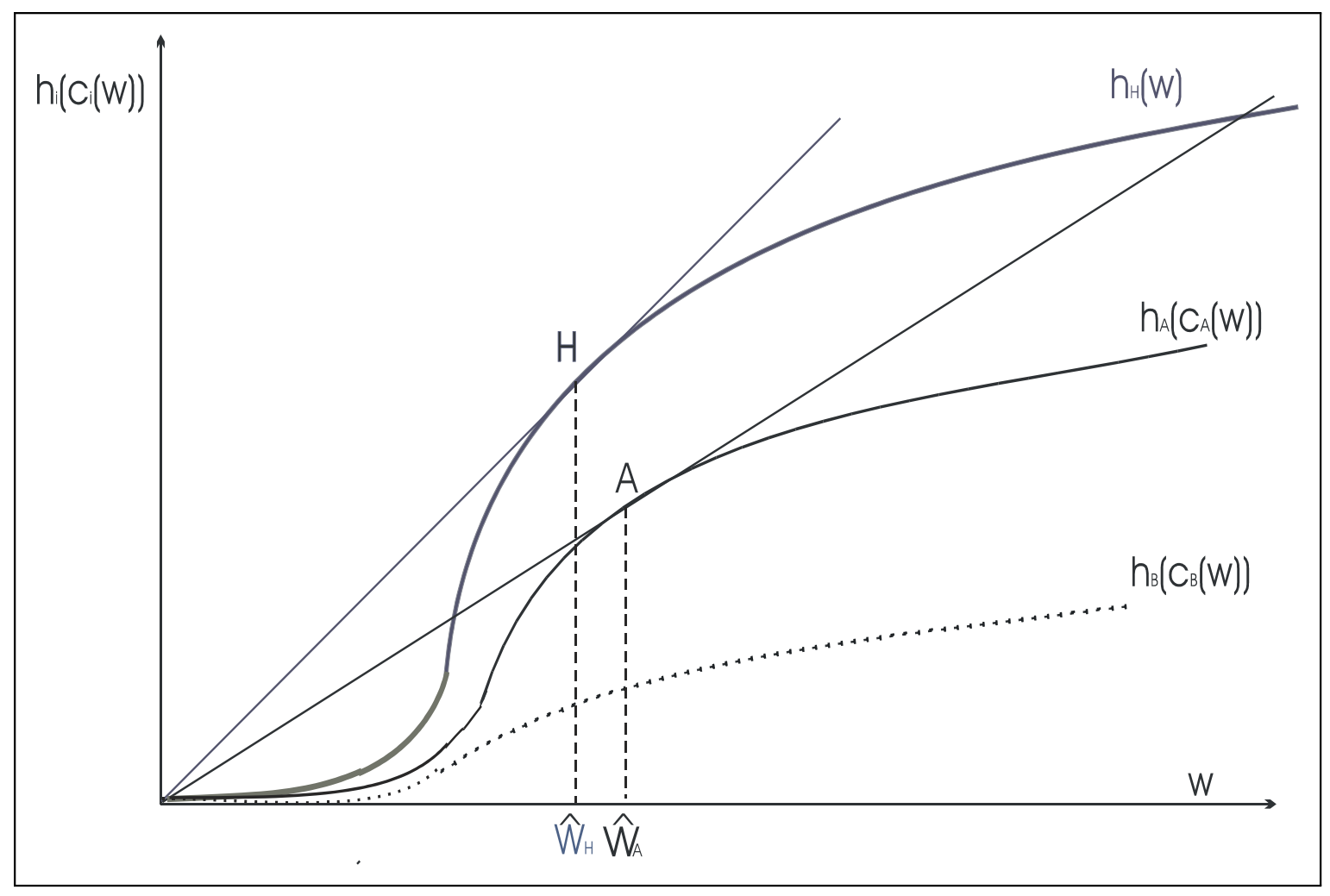

Figure 1: Household Labor when $g=0$

Endogenous Alternative Source of Income. Alternative sources of income available to households may sometimes depend on the efficiency of the agent who earns it, such as for instance poaching or home production. To study the effect of an endogenous alternative source of income, we need to introduce additional notation.

Let $\varphi(h)$ be the home production technology available to the households, where $h$ is the number of efficiency units used in the production, $\varphi(0)=0, \varphi^{\prime}(h) \geq 0$ and $\varphi^{\prime \prime}(h) \leq 0$. For simplicity, assume that households do not internalize the effect of their consumption on the home production. If household member $i$ is employed while the follows from $\frac{h_{A}\left(\widehat{c}_{A}\right)}{\widehat{c}_{A}} \geq \frac{h_{A}\left(c_{A}\right)}{c_{A}}$ that $\frac{h_{A}\left(\widehat{c}_{A}\right)}{\widehat{c}_{A}}>\frac{h_{H}\left(\widehat{w}_{H}\right)}{\widehat{w}_{H}}$. Second, if $\frac{h_{A}\left(c_{A}\right)}{c_{A}} \leq \frac{h_{B}\left(c_{B}\right)}{c_{B}}$ then $\frac{h_{B}\left(c_{B}\right)}{c_{B}} \geq$ $\frac{h_{H}\left(\widehat{w}_{H}\right)}{\widehat{w}_{H}}$. It follows from $\frac{h_{A}\left(\widehat{c}_{A}\right)}{\widehat{c}_{A}}>\frac{h_{B}\left(\widehat{c}_{B}\right)}{\widehat{c}_{B}}$ and the definition of $\widehat{c}_{B}$ that $\frac{h_{A}\left(\widehat{c}_{A}\right)}{\widehat{c}_{A}}>\frac{h_{H}\left(\widehat{w}_{H}\right)}{\widehat{w}_{H}}$. Hence the highest efficiency per unit of cost of a childless adult is always more than the highest efficiency per unit of cost of a household. 
other member works at home, the household income would be $Y=w_{i}+\varphi\left(h_{-i}\left(c_{-i}(Y)\right)\right)$, where $i \neq-i \in\{A, B\}$. This corresponds to a wage $w_{i}=Y-\varphi\left(h_{-i}\left(c_{-i}(Y)\right)\right)$ to be paid to household member $i$. Hence, an employer hiring labor of type $i$ would choose $Y$ in order to maximize

$$
\frac{h_{i}\left(c_{i}(Y)\right)}{Y-\varphi\left(h_{-i}\left(c_{-i}(Y)\right)\right)} \text { for } i \neq-i \in\{A, B\} \text {. }
$$

Let $\widehat{Y}_{i}$ denote the result of this maximization and let $\widehat{w}_{i}(\varphi)=\widehat{Y}_{i}-\varphi\left(h_{-i}\left(c_{-i}\left(\widehat{Y}_{i}\right)\right)\right)$ denote the corresponding wage for $i$. $\widehat{w}_{i}(g)$ is the efficiency wage for an exogenous alternative source of income as defined in (3.5).

Similarly to Proposition 1, the level of the alternative source of income clearly matters in comparing household labor with child or adult labor. However, two additional effects arise when the alternative source of income is endogenous. The first effect is that, at "comparable level" of alternative source of income, having an endogenous source of alternative income raises the efficiency wage for child labor or for adult labor.

OBSERVATion 2 If $\varphi\left(\widehat{w}_{i}(g)+g\right)=g$, then $\widehat{w}_{i}(\varphi)>\widehat{w}_{i}(g)$.

Proof. From the first-order condition for (3.5), we see that $\widehat{w}_{i}(g)$ is such that $h_{i}^{\prime} c_{i}^{\prime}(Y-$ $g)-h_{i}=0$. Now, the first-order condition for (3.9) tells us that $\widehat{Y}_{i}$ is such that $h_{i}^{\prime} c_{i}^{\prime}(Y-$ $\varphi)-h_{i}+h_{i} \varphi^{\prime} h_{-i}^{\prime} c_{-i}^{\prime}=0 .{ }^{17}$ The first two terms are the same, but the last term in the latter equation represents an additional benefit of paying a higher wage: its positive impact on the alternative source of income. Higher wages increase income, and thus consumption, directly and indirectly. Hence, the child and adult efficiency wages are larger, $\widehat{w}_{i}(\varphi)>\widehat{w}_{i}(g)$.

The second additional effect of an endogenous alternative source of income is a tradeoff when comparing child and adult labor. Adult labor is more productive than child

\footnotetext{
${ }^{17}$ It can easily be checked that the problem (3.9) is concave.
} 
labor not only in the employer's job but also in home production. Therefore, employers compare the a priori higher efficiency of adults in the job and the low alternative source of income from the children's home production, with a lower productivity of children in the job but whose cost is highly subsidized by the parents' home production. As a result, parental altruism has ambiguous effects. An increase in parental altruism can actually increase the efficiency per unit of cost of hiring adults only.

OBSERVATION 3 a has ambiguous effect on $\frac{h_{A}}{Y-\varphi\left(h_{B}\right)}$

Proof. We know from Proposition 1 that if $\phi$ is sufficiently flat, an increase in $\alpha$ decreases the efficiency of adult labor. Hence, we need to show that an increase in altruism $(\alpha)$ can actually increase the efficiency per unit of cost of hiring adults only. Assume that the nutrition efficiency curves take the following forms

$$
h_{A}(c)=h(c) \equiv\left\{\begin{array}{cc}
\ln (c) & c \geq 1 \\
0 & c<1
\end{array} \text { and } h_{B}(c)=\gamma h(c)\right.
$$

Set $\gamma=.9, \alpha=0.3$, and assume the home production to be $\varphi(h)=2(h)^{1 / 2}$. The income level that maximizes adult efficiency per unit of cost is $\widehat{Y}_{A}=4.65$. Using the envelope theorem, it is easy to see that the effect of $\alpha$ on (3.9) is positive if

$$
h^{\prime}\left((1-\alpha) \widehat{Y}_{A}\right)\left[\widehat{Y}_{A}-\varphi\left(\gamma \widehat{Y}_{A}\left(\alpha \widehat{Y}_{A}\right)\right)\right]-h\left((1-\alpha) \widehat{Y}_{A}\right) \varphi^{\prime}\left(\gamma h\left(\alpha \widehat{Y}_{A}\right)\right) \gamma h^{\prime}\left(\alpha \widehat{Y}_{A}\right)<0 .
$$

In our example, the left-hand side of this inequality takes value $-0.296,81$. Adults are preferred to children, but an increase in parental altruism $\alpha$ increases the efficiency per unit of cost of employing adult labor.

Note that an endogenous versus exogenous alternative source of income could be a useful way to compare child labor in rural areas, where alternative sources of income are 
likely to be some form of home production, and in urban areas, where public assistance and begging are more common.

For the remainder of the paper, we shall assume that there is no alternative source of income $g=0$ and that parents do not feed their children more than themselves, $\alpha \leq 1 / 2$, so that we can focus on the trade-off between adult and household labor.

Piece-Rate. Introducing piece-rates or incentive schemes in which the remuneration is contingent on the laborer's production, instead of a time wage, may also help in a context where nutrition efficiency matters. By making households aware of the effect of their consumption on their productivity, parents internalize part of the externality and choose an income distribution more in line with the employer's interest. ${ }^{18}$

OBSERVATION 4 In the absence of risk, piece-rates are always preferred by employers.

Proof. Assume that there is no risk, $\varepsilon=0$. Denote by $\sigma$ the piece-rate component of the remuneration, or share of the total output given to the household, and $F$ the constant part of the labor remuneration. The household's problem is then to maximize $U\left(c_{A}, c_{B}, l_{A}, l_{B}\right)$ subject to $c_{B}=\sigma f\left(l_{A} h_{A}+l_{B} h_{B}+H_{-i}\right)+F-c_{A}$ where $H_{-i}$ is the total efficiency units from the other employees. Hence, consumptions are such that

$$
(1-\alpha) c_{B}-\alpha c_{A}+\alpha c_{A} \sigma f^{\prime}(H) \frac{d H}{d c_{A}}=0
$$

In the absence of incentive scheme $(\sigma=0)$, the last term is 0 and households set the marginal rate of substitution between child and adult consumptions at one. In contrast, if $\sigma>0$ for the same level of household income the last term shows that the consumption allocation is biased toward the interest of the firm since it increases $f(H)$.

\footnotetext{
${ }^{18}$ Mirrlees (1975) and Stiglitz (1976) have pointed out that poor farming households may find optimal to distribute income unequally among their members due to the increasing returns in productivity.
} 
However in the presence of risk, fluctuations in consumption affect labor efficiency which affects production. The effect of fluctuations in consumption on $h$ is ambiguous as it is convex at low level of consumptions, while the effect of fluctuations in $h$ on the production is clearly negative as the latter is concave. If the overall effect is negative, this would limit the level of incentive that is desirable or even feasible. Note that this is the familiar trade-off between risk and incentive in employment contracts, however it is worth noting that the effect of risk does not come from the preferences here.

Technological Progress. Some empirical regularities have been reported concerning the labor supply among poor households. ${ }^{19}$ On the one hand, the reservation wage for labor participation of adults seems extremely low, generating an inelastic labor supply. On the other hand, the labor supply of children seems to be responsive to the income level. At extremely low levels of income, parents would prefer their child to work. However once a certain level of earnings is insured, parents prefer to withdraw their children from the labor supply. Basu and Van (1998) called this the luxury axiom. Supporting evidence for the luxury axiom are presented, among others, by Ray (2000) for Peru and Pakistan, Addison et al (1997) for Ghana and Pakistan, and Bhalotra (1999) for Pakistan. The following assumptions, $A 2$ and $A 3$, are made on our preferences (3.1) in order to capture the described patterns:

A2. $v_{A}(Y)=0$ for all $Y$. [Inelastic adult labor supply]

A3. $\lim _{Y \rightarrow \infty} v_{B}(Y)=\infty$. [Luxury axiom].

As shown by Basu and Van (1998), the luxury axiom can give rise to multiple equilibria. As our intent is not to focus on multiple equilibria, when they arise we select the employer's preferred equilibrium. ${ }^{20}$

\footnotetext{
${ }^{19}$ See among others, Goldin (1978), Heywood (1988), Nardinelli (1990), Grootaert and Kanbur (1995), and Horrell and Humphries (1995).

${ }^{20}$ Selecting the household's preferred equilibrium would not affect the above result, except for in some case lowering the level of technology at which child labor vanishes.
} 
Let a parameter $t$ enter the production function $f(H, t)$ to represent technological progress (or capital accumulation) in the following sense. As $t$ increases, the marginal productivity of labor increases, $f_{12}(H, t)>0$. Using this concept of technological progress, the following observation characterizes its effect on the incidence of child labor.

Observation 5 Under assumptions $\boldsymbol{A} 2-\boldsymbol{A} 3$, (i) persistent technological progress generates an initial rise in the incidence of child labor; (ii) child labor persists as long as there is some unemployment, and (iii) there is a level of technology $\bar{t}$ such that for any $t>\bar{t}$ there is no child labor.

Proof. To show this, we need to look at both demand and supply of labor. Let's start with the labor supply. If $w_{A}(t)$ and $w_{H}(t)$ are the going wages for adult and household labor respectively, parents supply their child's labor when

$$
v_{B}\left(w_{H}(t)\right) \leq u\left(\beta w_{H}(t)\right)-u\left(\beta w_{A}(t)\right)
$$

where $\beta=\alpha^{\alpha}(1-\alpha)^{1-\alpha}$. To be sure, the outside opportunity for an adult whose child does not work is important in determining labor supply. If $w_{H}(t)>0$ and $w_{A}(t)=0$, the full household supplies labor since adults prefer their children to work rather than earn nothing, $\lim _{c \rightarrow 0} u(c)=-\infty$. In contrast, for large enough values of $w_{A}(t)$ parents would supply their own labor but not the labor of their children.

Now, let's introduce labor demand considerations to characterize the labor market equilibrium. As seen in Proposition 1, firms do prefer to employ households than adults alone and would not find it profitable to pay less than the efficiency wage. Hence, the equilibrium household wage is $w_{H}(t)=\max \left\{\widehat{w}_{H}, w_{H}^{*}(t)\right\}$ where $w_{H}^{*}(t)$ is such that $f_{1}\left(x h_{H}\left(w_{H}^{*}\right), t\right) h_{H}\left(w_{H}^{*}\right)=w_{H}^{*}$, and $x=\frac{n}{m}$ is the total number of households per firm. Let $\widehat{t}$ be such that $w_{H}^{*}(\widehat{t})=\widehat{w}_{H}$. For all $t<\widehat{t}$ there is an excess supply of households, 
and some households cannot find employment.

Define $\widetilde{t}$ implicitly by $f_{1}\left(x h_{H}\left(\widetilde{w}_{H}(\widetilde{t})\right), \widetilde{t}\right) h_{A}\left((1-\alpha) \widehat{w}_{A}\right)=\widehat{w}_{A}$. It is easy to check that $\widehat{t} \leq \widetilde{t}$. Recall that firms would not pay adult labor less than the adult efficiency wage $\widehat{w}_{A}$. Hence, for $t<\widetilde{t}$, as long as households supply their labor, there is no demand for adult labor only. Unemployed adults would not find employment, so that the adult reservation wage is $w_{A}(t)=0$ and full households supply their labor. What does this imply for the incidence of child labor as $t$ increases ? As long as $t<\widehat{t}$, as the marginal productivity of labor increases with $t$, household employment, and therefore child labor, increases.

For $t \geq \tilde{t}$, unemployed adults would find work and the adult reservation wage is then $w_{A}(t)$ such that $f_{1}(H, t) h_{A}\left(w_{A}\right)=w_{A}$ (since for $\left.t \geq \tilde{t}, w_{A}(t) \geq \widehat{w}_{A}\right)$. Now notice that both the household wage and the adult reservation wage increase with $t$, and full employment prevails. Since $h_{i}(c)=\bar{h}_{i} \forall c \geq \bar{c}_{i}$, for large values of t the right-hand side of (3.12) tends to $u\left(\beta f_{1}(H, t)\left(\bar{h}_{A}+\bar{h}_{B}\right)\right)-u\left(\beta f_{1}(H, t) \bar{h}_{A}\right)<M$ for some finite $M$. Moreover, it follows from the luxury axiom that the left-hand side of the inequality tends to infinity. Hence there is technology level $\bar{t} \geq \widetilde{t}$ such that for any $t>\bar{t}$ there will be no child labor.

Since full employment is needed for $w_{A}(t)>0$, child labor persists as long as there is some unemployment.

There is a critical difference in wage determination depending on whether there is excess labor supply or excess labor demand. If there is an excess labor supply, parents supply their and their children's labor rather than being unemployed and earning nothing. Moreover, we know from Proposition 1 that, if reservation wages are not binding, employers prefer to employ households and pay them the efficiency wage $\widehat{w}_{H}$. There is then a degree of freedom in the wages since firms care only about the total amount paid to the household. Individual wages are undetermined and equilibrium adult and child 
wages under household labor are any pair whose sum is $\widehat{w}_{H}{ }^{21}$

\section{Welfare Analysis and Policy Implications}

Different policy interventions concerning child labor can be assessed in light of the above framework.

A popular policy intervention is a ban on child labor. Yet, in situations in which a large share of the population is below a nutritionally defined poverty line, a ban is often deemed undesirable. It is argued that, unless the labor demand is inelastic, such legislation would further reduce poor households' earnings, thereby hurting the very ones it tries to help. However, we can see that a ban could improve households' welfare. Employers would employ adults only and pay them at least their efficiency wage $\widehat{w}_{A}$ (point $A$, in Figure 1). The adult efficiency wage can be higher or lower than the household efficiency wage $\widehat{w}_{H}$, resulting in either an increase (as in Figure 1) or decrease in income for households in which the adult is employed. The effect on adult employment is also ambiguous and depends on the production function. Hence, there are environments in which a ban on child labor increases both total income for households with an employed adult and adult employment, thereby making all households better off.

With child labor and low income being correlated, providing resources to child laborers may seem like a good way to target aid to poor households. ${ }^{22}$ Yet, under widespread undernourishment, this policy is far from decreasing the appeal of child labor. Indeed, by shifting the household cost-productivity curve in Figure 1 to the left, it decreases more than proportionally the household efficiency wage. Employers clearly benefit from the intervention since labor costs are lower. As long as unemployment prevails, the total

\footnotetext{
${ }^{21}$ This degree of freedom implies that there is inverse relationship between the adult and the child wage. Such negative correlation is found by Parsons and Goldin (1989).

${ }^{22}$ As recommended in Grootaert and Kanbur (1995), p. 197.
} 
income of employed households decreases and child labor increases. The intervention reduces household unemployment but the amplitude of this effect depends on the elasticity of labor demand to labor costs. The framework developed here also warns us about unemployment funds or public assistance directed exclusively to adults. Indeed, it might result in a preference of employers toward child labor whose cost would be "subsidized" by the unemployment benefits through the intra-household redistribution.

The most attractive policy would be a combination of transfers to children conditional on them not working (for instance contingent on school attendance such as Progessa) and unemployment benefits at the level of the household or a minimum guaranteed income. An increased alternative source of income for children only renders adult labor relatively more attractive, and unemployment benefits help the households in which the adult is unemployed. Such policies have the potential to eradicate child labor.

\section{Conclusion}

This paper shows that, when malnutrition exists in the labor force, consumption decisions within the household affect the relative productivity of its members. This generates externalities in the labor market that modifies employers preferences towards family labor, even if there is excess supply of labor and children are less productive than adults. Parents supply their children's labor, as employers would otherwise not hire them. Paradoxically parent's altruism is shown to increase the likelihood of child labor. This study provides a new explanation for child labor which may shed some light on the 18th and 19th century practice of hiring entire families in the US and in England. The study also shows how technological progress would result in an initial increase in child labor levels and later a very rapid decline, a pattern observed in most countries during the industrial revolution. 


\section{References}

[1] Addison, T., S. Bhalotra and C. Heady (1997) 'Child labor in Pakistan and Ghana,' mimeo, University of Warwick.

[2] Anderson, M. (1971) Family Structure in the Nineteenth Century Lancashire. Cambridge University Press, England.

[3] Baland, J.-M. and J.A. Robinson (2000) 'Is Child Labor Inefficient.' Journal of Political Economics 108(4), 663-79.

[4] Basu, K. (1992) 'The Broth and the Cooks: A Theory of Surplus Labor.' World Development 20(1), 109-17.

[5] Basu, K. (1999) 'Cause, Consequence and Cure, with Remarks on International Labor Standards.' Journal of Economic Literature 37(3), 1083-1119.

[6] Basu, K. and P.H. Van (1998) 'The Economics of Child Labor.' American Economic Review 88(3), 412-27.

[7] Bhalora, S.(2001) 'Is Child Labor Necesary?' London School of Economics - Suntory Toyota, Development Economics Research Programme, Working Paper 26.

[8] Bliss, C. and N. Stern (1978) 'Productivity, Wage and Nutrition. Part I: Policy. Part II: Some Observations.' Journal of Development Economics 5(4), 331-98.

[9] Bolin-Hort, P. (1989) Work, Family and the State: Child Labor and the Organization of Production in the British Cotton Industry, 1780-1920. Lund University Press, Sweden.

[10] Clark, C. and M. Haswell (1970) The Economics of Subsistance Agriculture. New York: St. Martin's Press.

[11] Cruickshank, M. (1981) Children and Industry. Manchester University Press, Manchester.

[12] Cunningham, H. (1990) 'The Employment and Unemployment of Children In England c. 1680-1851.' Past and Present 126, 115-50.

[13] Cunningham, H. and P.P. Viazzo (1996) Child Labor in Historical Perspective, 1800-1985: Case Studies from Europe, Japan and Colombia. UNICEF, Florence.

[14] Dasgupta, P. and D. Ray (1986) 'Inequality as a Determinant of Malnutrition and Unemployment: Theory.' Economic Journal 96(384) 1011-34.

[15] Dasgupta, P. and D. Ray (1987) 'Inequality as a Determinant of Malnutrition and Unemployment: Theory.' Economic Journal 97, 177-88.

[16] Dasgupta, P. (1993) An Inquiry Into Well-Being and Destitution. Clarendon Press, New York. 
[17] Dasgupta, P. (1997) 'Nutritional Status, the Capacity for Work and Poverty Traps.' Journal of Econometrics 77(1), 5-38.

[18] Freedom For Hunger Campaign (1962) 'Nutrition and Basic Efficiency.' Basic Study 5, Food and Agricultural Organization, Rome.

[19] Fogel, R. and S. Engerman (1974) Time on the Cross: The Economics of American Negro Slavery. Boston, MA: Little, Brown and Co.

[20] Foster, J.O. (1967) Capitalism and Class Consciousness in Earlier Nineteenth Century Oldham. Ph.D. Dissertation, University of Cambridge.

[21] Foster, A. and M. Rosenzweig (1993) 'Information Flows and Discrimination in Labor Markets in Rural Areas in Developing Countries.' Proceedings of the World Bank Annual Conference on Development Economics 1992, 173-204.

[22] Foster, A. and M. Rosenzweig (1994) 'A Test for Moral Hazard in the Labor Market: Effort, Health and Calorie Consumption.' Review of Economics and Statistics 76(2), 21327.

[23] Goldin, C.D. (1978) Household and Market Production of Families in a Nineteenth Century American City. Princeton University Press, Princeton.

[24] Grootaert, C. and R. Kanbur (1995) 'Child Labor: An Economic Perspective.' International Labor Review 134(2),187-203.

[25] Guha, A. (1989) 'Consumption, Efficiency and Surplus Labour.' Journal of Development Economics 31, 1-12.

[26] Hall, J.D., R. Korstad and J. Leloudis (1986) 'Cotton Mill People: Work, Community and Protest in the Textile South, 1880-1940.' Journal of American History 29(2), 245-86.

[27] Heywood, C.M. (1988) Childhood in 19th-Century France. Work, Health and Education Among the "Classes Populaires." Cambridge University Press, New York.

[28] Horrell, S. and J. Humphries (1995) 'The Exploitation of Little Children: Child Labor and Family Economy.' Exploration in Economic History 32(4), 485-516.

[29] Immink, M. and F.E. Viteri (1981) 'Energy Intakes and Productivity of Guatemalan Sugar cane Cutters: An Empirical Test of the Efficiency Wage Hypothesis, Parts I and II.' Journal of Development Economics 9(2), 251-87.

[30] Keys, A. and others of the Laboratory of Physiological Hygiene, University of Minnesota (1950) The Biology of Human Starvation. University of Minnesota Press, Minneapolis.

[31] Leibenstein, H. (1957) Economic Backwardness and Economic Growth. Wiley \& Sons, New York. 
[32] Marx, V.K. (1867) Das Kapital: Kritiek der Politishen Oekonomie, 3d ed. translated by S. Moore and E. Aveling (1983), International Publishers, New York.

[33] Mirrlees, J.A. (1975) 'A Pure Theory of Underdeveloped Economies.' In L. G. Reynolds (Ed.), Agriculture in Development Theory, Yale University Press, New Haven, 83-106.

[34] Nardinelli, C. (1980) 'Child Labor and the Factory Acts.' Journal of Economic History 40(4), 739-55.

[35] Parsons, D.A. and C. Goldin (1989) 'Parental Altruism and self-interested Child Labor among Late Nineteenth-Century American Families', Economic Inquiry 27(4), 637-59.

[36] Ray, D. and P. Streufert (1993) 'Dynamic Equilibria with Unemployment due to Undernourishment.' Economic Theory 3, 61-85.

[37] Ray, R.(2000) 'Analysis of Child Labour in Peru and Pakistan.' Journal of Population Economics 13, 3-19.

[38] Rodgers, G.B. (1975) 'Nutritionally Based Wage Determination in the Low-Income Labour Market.' Oxford Economic Papers 27(1), 61-81.

[39] Saxonhouse, G.R. and G. Wright (1984) 'Two Forms of Cheap Labor in Textile Factory.' Research in Economic History, Sup. 3.

[40] Shammas, C. (1990) The Pre-industrial Consumer in England and America. Clarendon Press, Oxford.

[41] Stiglitz, J.E. (1976) 'The Efficiency Wage Hypothesis, Surplus Labour and the Distribution of Income in L.D.C.'s.' Oxford Economic Papers 28(2), 185-207.

[42] Strauss, J. and D. Thomas (1998) 'Health, Nutrition, and Economic Development.' Journal of Economic Literature 36(2), 766-817.

[43] U.S. Senate Documents n.645 (1910-11) Report on the Condition of Women and Child Wage-Earners in the United States in 19 volumes. 61st Congress $2 \mathrm{~d}$ session, Government Printing Office, Washington.

[44] Wallace, A. (1978) The Growth of an American Village on the Early Industrial Revolution. Knopf, New York.

[45] West, S.E. (1826) Price of Corn and Wages of Labour, with Observations upon Dr. Smith's, Mr. Ricardo and Mr. Malthus's Doctrines upon these Subjects, etc. London.

[46] Wolgemuth, J.C. et al. (1982) 'Worker Productivity and the Nutritional Status of Kenyan Road Construction Labor.' American Journal of Clinical Literature 36(7), 68-78. 